
\title{
$\begin{array}{ll}\text { Research Square } & \begin{array}{l}\text { Preprints are preliminary reports that have not undergone peer review. } \\ \text { They should not be considered conclusive, used to inform clinical practice, } \\ \text { or referenced by the media as validated information. }\end{array}\end{array}$
}

\section{The lessons of COVID-19 pandemic for communicable diseases surveillance system: A qualitative study in the Kurdistan region-Iraq}

\section{Soran Amin Hamalaw}

SPU: Sulaimani Polytechnic University

Ali Hattem Bayati

Sulaimani Polytechnic University

Muhammed Babakir-Mina

Sulaimani Polytechnic University

Amirhossein Takian ( $\nabla$ takian@tums.ac.ir)

School of Public Health, Tehran University of Medical Sciences

\section{Research}

Keywords: COVID-19 pandemic, communicable diseases, surveillance system, Iraq

Posted Date: February 26th, 2021

DOI: https://doi.org/10.21203/rs.3.rs-242487/v1

License: (1) This work is licensed under a Creative Commons Attribution 4.0 International License. Read Full License 


\section{Abstract}

Background Coronavirus disease 2019 (COVID-19) has revealed a series of unprecedented challenges to Communicable Disease Surveillance Systems (CDSS) globally. This study aimed to determine the opportunities of and barriers to CDSS during the COVID-19 pandemic, and the extent to which the disease integrated into the CDSS in the Kurdistan region of Iraq. Methods A descriptive qualitative approach was applied. We conducted 7 semi-structured interviews and one focus group discussions (FGD) with purposefully identified Key Informants (KI) from June to December 2020. All interviews were digitally recorded and transcribed verbatim. We adopted a mixed deductive-inductive approach for thematic analysis of data, facilitated by using MAXQDA20 software for data management. Results Although the CDSS was considered appropriate and flexible, the COVID-19 was interpreted not to be integrated into the system due to political concerns. The lack of epidemic preparedness, timeliness, and partial cessation of training and supervision during the pandemic were the main concerns regarding core and support activities. The existence of reasonable surveillance infrastructure, i.e. trained staff was identified as an opportunity for improvement. The main challenges include: staff deficiency, absence of motivation and financial support for present staff, scarce logistics, managerial and administrative issues, and lack of cooperation, particularly among stakeholders and surveillance staff. Conclusion Our findings revealed that due to political barriers, COVID-19 was not integrated into the CDSS. It also highlighted the main facilitators of and barriers to CDSS in the region. We advocate health authorities and policy-makers to prioritize the surveillance and effective management of communicable diseases.

\section{Introduction}

The principal source of infectious diseases is typically from various pathogens comprising of: bacteria, viruses, fungi, and parasites. By virtue of their minuscule architecture and swift mode of spreading, there is always a potential risk that a known or unknown pathogen may evolve and spread rapidly to harm any population at any moment. Even with advanced safety measures and historical medical progress, infectious diseases are arising with more deadly consequences worldwide (1). What happened in Wuhan, Hubei Province, China, on 31 December 2019 is a true story of the threat of infectious diseases on humanity, when a

cluster of pneumonia cases of unknown aetiology was identified. Subsequently, the novel coronavirus, Severe Acute Respiratory Syndrome Coronavirus 2 (SARS-CoV-2) was announced as the causative agent of this acute respiratory disease, so-called coronavirus disease 2019 (COVID-19) on 9 January 2020 by Chinese Centre of Disease Control and Prevention (CDC). On 11 March, 2020, the World Health Organization (WHO) declared COVID-19 a pandemic(2,3), which has affected 223 Countries, areas, or territories, with over 104 million confirmed cases, and more than 2.29 million confirmed deaths todate (4).

CDSS is considered an essential public health mechanism to prevent and control infectious diseases. Surveillance has been defined as "the ongoing, systematic collection, analysis, and interpretation of healthrelated data, which is the cornerstone of planning, implementation, and evaluation of public health practice"(5)(6). The early detection of infectious disease is a fundamental step for a quick response to outbreaks, which is in turn the primary purpose of CDSS to minimize the size of the outbreak and reduce overall mortality and morbidity related to the disease ultimately. Effective assessment of the surveillance 
system and its competence is vital to ensure the availability of accurate information for evidence-informed decision making at the right time and limit the communicable diseases' threat.

Investments in infectious disease surveillance and investigations are poorly allocated globally (7). Worse still, in the context of low and middle-income countries (LMICs), the capacity and available infrastructure for prevention and timely detection of communicable diseases is generally lower than high-income countries (HICs) (8). As the most devastating threat to human societies after World War II, COVID-19 has illustrated the urgent need to strengthen the CDSS anywhere, particularly in the LMICs (9). In Iraq, especially after the US invasion in 2003, as the burden of communicable diseases has been raising, the demands for improving the surveillance system has increased (10-12). The Kurdistan region is located in the north of Iraq and governed by the Kurdistan regional government. However, the CDSS in the Kurdistan region is centralized and directed by the Iraqi ministry of health under the WHO supervision. Despite substantial efforts to enhance CDSS capability for early detection and effective management of outbreaks, there is limited evidence on how to do so in this context $(13,14)$.

To the best of our knowledge, little evidence exist about the assessment of the CDSS in Iraq (15), while the CDSS was never assessed in the Kurdistan region. Our knowledge is scarce about the functioning and drawbacks in the CDSS system, its response to the current challenges and the real-time requirements. Therefore, following the principle of "What is worth doing is worth doing right", providing an overview of the CDSS performance during outbreak emergencies and the assessment of the current CDSS in Kurdistan-Iraq was a necessary benchmark data to evaluate its effectiveness and areas in need of further development (16).

Human resource for health (HRH) are the main pillar in the delivery of high-quality services. They also play a central role in the CDSS, whose voice should be heard and their views should be taken into consideration to improve the CDSS. This Qualitative study aims to assess the core functions, barriers to and strengths of the surveillance system according to the staff's perspective during the COVID19 pandemic in the Kurdistan region- Iraq. Our findings and evidence-based policy recommendations will enhance, we envisage, the flexibility and competency of the CDSS system towards a better response to the ongoing COVID-19 crisis as well as likely pandemics to come, in Kurdistan-Iraq and perhaps similar LMICs (17).

\section{Methodology}

\section{Design}

This is a descriptive qualitative research, which is appropriate approach to produce more valuable outcomes when attempting to anticipate the desirable characteristics of a changing system, as well as to help increase the probability of compliance (18). This approach allowed us to utilize a naturalistic perspective for the interpretation of the subject of study by accessing the meanings ascribed by the participants (19). Our qualitative design helped provide insights and understanding of the surveillance activities through the lenses of staff experience during the COVID19 pandemic.

\section{Settings}

This study was conducted from June to December 2020, in the Kurdistan region of Iraq. 


\section{Participants and eligibility}

We used open-ended semi-structured interviews and FGDs for data collection. All staff working with the communicable disease surveillance system was eligible to participate in this study. A purposeful sampling method was used to recruit a total of $14 \mathrm{KIs}$, seven in one FGD and seven individual in-depth interviews. The key informant stakeholders provided valuable information to uncover more details about their experiences in the CDSS during the COVID-19 pandemic. Respondent included surveillance managers, surveillance professionals, surveillance executive team members, and other communicable disease surveillance staff from Erbil, Sulaimani, Duhok, and Halabja provinces. Please see Table 1 for characteristics of study participants.

\section{Data collection and data analysis}

Based on a comprehensive review and consultations with key experts, we developed a generic interview guide for data collection, as you see in Appendix1. The interview guide had three parts: 1) the existence of CDSS in Kurdistan and its flexibility, meaning the system adaptability to changing information needs or operating conditions with little additional cost in time, personnel, or allocated funds"(20); 2) the core functions of the system during COVID19 epidemic including case detection, case confirmation, reporting, feedbacks and supervision, training, and epidemic preparedness; and 3) staff's views regarding barriers to and strengths of the surveillance system and their recommendations for improvement. Each interview lasted for 30-45 minutes, while the FGD lasted 80 - 90 minutes. The interviews, which were conducted in the Kurdish language and then translated to English, were recorded and transcribed verbatim. One author (S. H.) checked the accuracy of transcript against voice records. Data collection continued until we reached data saturation and no new theme or concept emerged. A mixed deductive-inductive content analysis strategy was used for data analysis. We used MAXQDA version 20.3 for data storage and management. After familiarization with the data, one author (A. B.) began to identify the main themes and organized them in different categories. The emerging themes were actively reviewed to reflect the research questions. The topics and ideas referred to as a coding index were noted and ordered, and then were grouped to initiate themes. The codes and themes reviewed against available data systematically and the themes with insufficient database support were excluded or refined.

\section{Ethical considerations}

The permission to perform this study was issued by the Ethics Committee of the Sulaimani Polytechnic University with the project number $\mathrm{CH} 00036 / 1 / \mathrm{June} / 2020$. The interviewer explained the purpose of the study to the participants at the beginning of each interview. The participants were asked to sign an informed consent. Participants' involvement in the study was voluntary. The anonymity and confidentiality of the participants were ensured and maintained throughout this study.

\section{Results}

Our analysis revealed seven main themes, which were classified into sub-themes and codes as presented in Table 2 and Table 3.

\section{Staff's perspective about CDSS}


Our participants mentioned that despite appropriate and active communicable disease surveillance system in the Kurdistan region of Iraq, it is not perfect:

"in my view there is a system, and it is active ... We belong to the Iraqi surveillance system, what is taking place here is the same as that in other parts of Iraq. Therefore, we have a good very good system but the question is to what extent the advantages of it were taken?" district surveillance director\#3.

The flexibility of the system was mentioned to be satisfactory, while the acceptability of the system by the stakeholders was ambiguous:

"The system is flexible and working, but not acceptable, not acceptable at all, the people do not use it... our system is working perfectly, has the capacity to involve Corona and other infectious diseases, but regarding using it, how much it has been used? it is another matter." surveillance managere\#5.

\section{Integration of COVID-19 into the communicable disease surveillance system}

Many participants complained that the COVID-19 was not integrated into the CDSS. Instead, a parallel system was used to report COVID-19 status to the health authorities. Only specified hospitals and health centers were responsible to report the disease. As put by the head of one of the district-level surveillance units:

"we dealt with covid-19 differently, they announced some staffs for it ... we create excel spreadsheet includes the patient name, age, address, symptoms and other information. We gave a copy of it to the ministry of health" district surveillance director\#1

"we don't deal with corona patients, if the patient was suspected the doctor will send him to other places to do tests. We don't record or report corona patient's" health centre surveillance staff\#6.

This was perhaps because of the dominancy of the political considerations in dealing with COVID-19 at the outset of the outbreak:

"at the beginning, the disease became a political issue, and the things went in that directions. The things were not as we desired" district surveillance director \#1

\section{Core functions}

The presence of the case definition is critical for communicable diseases case detection. Respondents highlighted the importance of existing case definition for all surveillance priority diseases at the surveillance units. The COVID-19 case definition is adopted from WHO updates, but it is often not applied for case detection in health facilities:

"we as communicable disease department always depended on WHO case definition. Always we generalized the case definition to the health facilities but, they do not depend on it for case detection." district surveillance director\#13.

Case confirmation refers to the capacity of appropriate specimen collection, packing, transportation and laboratory testing. Most participants mentioned that case confirmation of COVID-19 was convincing: 
"We cannot generalize, we talked about here, the lab was okay, I work, here from PPE, materials, sticks, and transportation to the tests. There was no problem" surveillance executive staff\#2, "all materials for testing were there and there was no shortage and even if there was, we overcome it" surveillance executive staff\#12. One of the difficulties was the magnitude of the problem which outweighed the laboratory capacity. "You know lab work, if we compared the load of the problem with the lab capacities power laboratories had lower capacities... how many suspected cases do we have? Daily we have a lot but how many samples we could take? a few, so for a while when much more samples were taken, out of the lab capacities, more than 2 weeks were needed to get the results." district surveillance director\#3.

The mechanism of reporting was clear and straightforward, but the timeliness was an issue due to insufficient non-electronic system:

"the reporting was very clear and obvious, indeed when there is a COVID-19 case, how to refers it and to where? how to do tests? and who reports and to where? is clear ...but is it timely?"district surveillance director\#13.

"it wasn't arriving on time. It was hard copy paper work, not software or electronic reporting, it was needing time." District surveillance manager\# 11

Regarding data analysis, respondents disclosed that hospitals and health centres do not perform data analysis, which is only conducted at the national and district levels:

"We do not analyze the data; we send the data to ... (the directorate of prevention) she will perform the analysis" surveillance executive staff in\#8.

Reflecting upon the insufficient preparedness plan to face pandemics and other communicable diseases emergencies, a district surveillance director said "in CDC in our district there is no prepared plan for communicable disease emergencies. We in ... think every 2-3 years there is an outbreak of cholera so we prepare for cholera outbreak. But for other infectious diseases emergencies there is no plan" district surveillance director \#13.

The participants believed that the feedbacks with their scarcity were good and informative "Generally, the feedbacks were good and useful at the beginning they had some comments about our performance, because of some problems in our data. Then those issues were overcome. Otherwise, everything was good." District surveillance director\#1

\section{Support functions}

Many interviewees acknowledged regular supervision and training for staff in the past, which reduced significantly during the COVID19 pandemic, except for some specific occasions. Some mentioned a training course that was held last year to build staff's capacity in using the Epi Info program, which is a free statistical software package for epidemiology developed by Centers for Disease Control and Prevention in Atlanta, Georgia, the USA. In addition to knowledge transfer and improving staff's skills, this course was a good opportunity to communicate with other staff in other surveillance locations. Unfortunately, the use of the Epi Info program has become optional due to the insufficient resources i.e. computer and internet access: 
"But the training was very good we met other staffs and was a good chance to communicate with other centres and change information. But this year due to corona there was no training" health centre surveillance staff\#6.

Cooperation among CDSS stakeholders (laboratory staffs, surveillance officers, doctors, sample collectors, infection control staffs, and others) was mentioned to be unsatisfactory. Let alone the lack of the trained staff for nasal swab collection.

\section{Strengths of the CDSS}

Our participants also identified several strengths of the current CDSS system, including: the existence of the system itself, presence of a trained staff who satisfied with their work in the CDSS, administrative support from the preventive directorate of health, national cooperation and support, accessibility, and convenience with Epi Info program to use for surveillance between the staffs and finally, the awareness of public concerning COVID-19:

"the first strong point of the system is the existence of the system itself. Second is the presence of the staff because the staff working in surveillance have experience and love their work, there is central cooperation, therefore, there is a central support" district surveillance director\#3.

\section{Barriers to implementing high-quality CDSS}

The interviewees recognized the following obstacles to the establishment of a high-quality CDSS: inadequate skilled staff, insufficient motivation and lack of financial support for surveillance staff, scarce logistics (computers and internet access), directorial and administrative issues, insufficient understanding of surveillance concept, and lack of cooperation, particularly between doctors and surveillance staff:

"absent of necessary staff, absent of required fund, the barriers regarding logistics, transportation and reductions of training and recent economic issues have a great effect that made the system to be weak" district surveillance manager\#11.

\section{Discussion}

COVID-19 crisis was an opportunity to assess the CDSS core and support functions during the pandemic. Our findings, which drew upon the key informants' detailed knowledge of the efficiency and functionality of the surveillance system (21), have shed some light on the challenges facing the CDSS in the Kurdistan region and provided reasonable suggestions for strengthening the system.

Our study also revealed although the existing surveillance infrastructure in Kurdistan region is not perfect with human and physical resources insufficiencies, it is flexible enough with the ability to adapt to the changing needs such as the removal or inclusion of additional diseases. Nevertheless, COVID-19 surveillance was expected to be integrated into CDSS, which allows the efficient use of human and other resources. As a result of political influences, health authorities preferred a parallel structure to report and respond to the pandemic, and therefore classified the related data as a national security. Similarly, the impact of political influence on public health decision-making was reported in England (22). 
Our findings also highlighted the absence of a standard case definition in health centres and hospitals, that might jeopardize case detection. A Singaporean study showed that case definition was the foundation to identify $20 \%$ of COVID-19 cases at general practitioner clinics or hospitals (23). This supports the previous study stated that 'during busy periods there is an assumption that surveillance is less critical than patient's care and could be 'deferred' and broad variance in the implementation of case definitions among hospitals and community clinics exists'(23). We assume applying a standard case definition in all health facilities will boost the overall sensitivity and specificity of CDSS, similar to a study on the Ebola epidemic (24).

Insufficient electronic infrastructure led to inappropriate reporting methods that affected the CDSS in Kurdistan. Similar results were reported in Yemen (25), Iran (26-28), and other settings (14). Similar to many LMICs, the COVID-19 surveillance capacity is restrained by inadequate resources and training (14). Further, the directorial incompetency, e.g. lack of meaningful cooperation between doctors and surveillance staff; and not prioritizing the surveillance program the ministry of health; hindered the CDSS in Iraq and its neighbours, i.e. Iran and Syria (29-31).

Strong and comprehensive CDSS is a building block for advance communicable disease reporting and response systems. Therefore, identification and reporting the weaknesses of the system may pave the way to fill the existing gaps by recruiting, motivating, and training staff, as well as allocating the cost-effective resources towards this task. Another study in Ghana also concluded that enhancing the attention to and awareness of surveillance activities among doctors, nurses, administrators, and laboratory workers is an urgent need to the surveillance overall functioning of the health system (14).

\section{Policy recommendations}

Participants pointed out six major recommendations to enhance CDSS in the Kurdistan Region, including: more training for surveillance staff; greater cooperation among various stakeholders; employing more staff for surveillance units; setting up a focal point in hospitals for surveillance, translating guidelines into the Kurdish language; and ensuring the availability of transportation and technological resources (Table 1).

Respondent appreciated the efforts from the Ministry of Health in Baghdad and surveillance units at the district levels in building up their capacities to address communicable diseases and health events in their localities through CDSS. However, there was an overwhelming consensus that more training is needed. The participants also recommended more communication and cooperation between Surveillance staff and those who hold the reins in the health system directors and doctors.

\section{Study limitations}

The interviews were conducted in the native Kurdish language and then translated into English, which might have affectd the data quality. We compared/contrasted our findings with other quantitative and qualitative approaches, that were not necessarily based on staff's point of view.

\section{Conclusions}


Our findings revealed that due to political barriers, COVID-19 was not integrated into the CDSS. It also highlighted the main facilitators of the CDSS that include the existence of reasonable surveillance infrastructure, i.e., trained staff, as an opportunity for improvement. We advocate health authorities and policy-makers to prioritize the surveillance and effective management of communicable diseases. To overcome the challenges of current COVID-19 crisis and prevent the deadly consequences of future likely pandemics, it would be crucial to provide strategic support, mainly through strengthening human resources for health as well as required infrastructure and logistics, and foster a meaningful intersectoral collaboration to strengthen the CDSS in any setting.

\section{Declarations}

\section{Acknowledgments}

We would like to specifically thank the Centres for Communicable Diseases Control in Directorates of Health in Kurdistan region of Iraq for their invaluable cooperation in data collection.

\section{Conflict of Interest}

The authors declare that there is no conflict of interests regarding the publication of this paper.

\section{Authors' contribution}

AT and MB conceived the study. MB supervised local data collection, analysis and data interpretation. SH and $A B$ conducted data collection and analysis. SH wrote the first draft of the manuscript. All authors read and contributed to the intellectual development of manuscript and approved its final version. AT is guarantor.

\section{References}

1. Akhter S, Akhtar S. Emerging coronavirus diseases and future perspectives. Vol. 31, VirusDisease. Springer; 2020. p. 113-20.

2. WHO. WHO Director-General's opening remarks at the media briefing on COVID-19 - 11 March 2020 [Internet]. [cited 2021 Feb 7]. Available from: https://www.who.int/director-general/speeches/detail/whodirector-general-s-opening-remarks-at-the-media-briefing-on-covid-19-11-march-2020

3. Wu Y-C, Chen C-S, Chan Y-J. The outbreak of COVID-19. J Chinese Med Assoc [Internet]. 2020 Mar [cited 2020 Sep 18];83(3):217-20. Available from:

http://journals.Iww.com/10.1097/JCMA.0000000000000270

4. WHO. Coronavirus disease (COVID-19) [Internet]. [cited 2021 Feb 7]. Available from: https://www.who.int/emergencies/diseases/novel-coronavirus-2019? gclid=Cj0KCQiAvP6ABhCjARIsAH37rbQwVrjJ8LV_GryGJSuZZN_09slza9wXJ0YfelP5eXkkHIR6e1d8xYaAtBrEALw_wcB

5. Centers for Disease Control and Prevention (CDC). Introduction to Public Health. In: Public Health 101 Series. Atlanta, GA: U.S. Department of Health and Human Services, CDC; 2014. [Internet]. CDC Public 
Health. 2014 [cited 2020 Sep 18]. p. 1. Available from:

https://www.cdc.gov/publichealth101/surveillance.html

6. Thacker SB, Berkelman R I. Public health surveillance in the United States. Epidemiol Rev [Internet]. 1988 Jan 1 [cited 2020 Jun 2];10(1):164-90. Available from: https://academic.oup.com/epirev/articlelookup/doi/10.1093/oxfordjournals.epirev.a036021

7. global trends supp. Global trends - supp. Nature [Internet]. 2008 Feb 21 [cited 2020 Apr 3];451(7181):990-3. Available from: http://www.ncbi.nlm.nih.gov/pubmed/18288193

8. Kandel N, Chungong S, Omaar A, Xing J. Health security capacities in the context of COVID-19 outbreak: an analysis of International Health Regulations annual report data from 182 countries. Lancet [Internet]. 2020 Mar 28 [cited 2021 Feb 7];395(10229):1047-53. Available from: https://doi.org/10.1016/

9. Raoofi A, Takian A, Sari AA, Olyaeemanesh A, Haghighi H, Aarabi M. COVID-19 pandemic and comparative health policy learning in Iran. Arch Iran Med [Internet]. 2020 [cited 2021 Feb 7];23(4):220-34. Available from: https://pubmed.ncbi.nlm.nih.gov/32271594/

10. Hussain AA, Lafta R. Trend of cholera in Iraq in the time of unrest. Mustansiriya Med J. 2019;18(1):1.

11. Jaff D. Brucellosis in Iraqi Kurdistan: An overview. $1113 \sim$ J Entomol Zool Stud [Internet]. 2016 [cited 2020 Apr 3];4(4):1113-5. Available from: http://www.who.int/csr/resources/publications/Brucellosi

12. Zhao Y, Lafta R, Hagopian A, Flaxman AD. The epidemiology of 32 selected communicable diseases in Iraq, 2004-2016. Int J Infect Dis. 2019 Dec 1;89:102-9.

13. Steele L, Orefuwa E, Dickmann P. Drivers of earlier infectious disease outbreak detection: a systematic literature review. Vol. 53, International Journal of Infectious Diseases. Elsevier B.V.; 2016. p. 15-20.

14. Ibrahim NK. Epidemiologic surveillance for controlling Covid-19 pandemic: types, challenges and implications. Vol. 13, Journal of Infection and Public Health. Elsevier Ltd; 2020. p. 1630-8.

15. Kadhum SA. Assessment of communicable diseases surveillance system activities in phc centers in Baghdad. Res Artic Kadhum World J Pharm Res www.wjpr.net [Internet]. 2019 [cited 2020 May 31];8(7):137. Available from: www.wjpr.net

16. Nsubuga P, White ME, Thacker SB, Anderson MA, Blount SB, Broome C V., et al. Public Health Surveillance: A Tool for Targeting and Monitoring Interventions [Internet]. Disease Control Priorities in Developing Countries. The International Bank for Reconstruction and Development / The World Bank; 2006 [cited 2020 Sep 19]. Available from: http://www.ncbi.nlm.nih.gov/pubmed/21250345

17. Denny E, Weckesser A. Qualitative research: what it is and what it is not. BJOG An Int J Obstet Gynaecol [Internet]. 2019 Feb 1 [cited 2020 Sep 15];126(3):369-369. Available from: http://doi.wiley.com/10.1111/1471-0528.15198

18. Girdler-Brown B V. Evaluation of the notifiable diseases surveillance system in South Africa. Vol. 59, International Journal of Infectious Diseases. Elsevier B.V.; 2017. p. 139-40.

19. Chafe R. The Value of Qualitative Description in Health Services and Policy ResearchValeur de la description qualitative dans la recherche sur les politiques et services de santé. Healthc Policy [Internet]. 2017 Dec 24 [cited 2020 Sep 15];12(3):12-8. Available from:

https://www.ncbi.nlm.nih.gov/pubmed/28277201\%0Ahttps://www.ncbi.nlm.nih.gov/pmc/PMC5344360/ 
20. Centers for Disease Control (CDC). Guidelines for evaluating surveillance systems. MMWR Suppl [Internet]. 1988 May 6 [cited 2020 Nov 25];37(5):1-18. Available from:

http://www.ncbi.nlm.nih.gov/pubmed/3131659

21. WHO. Communicable disease surveillance and response systems Guide to monitoring and evaluating [Internet]. 2006 [cited 2019 Jul 14]. Available from:

https://www.who.int/csr/resources/publications/surveillance/WHO_CDS_EPR_LYO_2006_2.pdf?ua=1

22. Kneale D, Rojas-García A, Thomas J. Obstacles and opportunities to using research evidence in local public health decision-making in England. Heal Res Policy Syst [Internet]. 2019 Jun 28 [cited 2020 Dec 2];17(1). Available from: https://pubmed.ncbi.nlm.nih.gov/31248422/

23. Ng Y, Li Z, Chua YX, Chaw WL, Zhao Z, Er B, et al. Evaluation of the Effectiveness of Surveillance and Containment Measures for the First 100 Patients with COVID-19 in Singapore - January 2-February 29, 2020. MMWR Morb Mortal Wkly Rep [Internet]. 2020 Mar 20 [cited 2020 Dec 4];69(11):307-11. Available from: http://www.cdc.gov/mmwr/volumes/69/wr/mm6911e1.htm?s_cid=mm6911e1_w

24. Hsu CH, Champaloux SW, Keïta S, Martel L, Bilivogui P, Knust B, et al. Sensitivity and specificity of suspected case definition used during West Africa ebola epidemic. Emerg Infect Dis [Internet]. 2018 Jan 1 [cited 2020 Dec 4];24(1):9-14. Available from: /pmc/articles/PMC5749454/?report=abstract

25. Sahal N, Reintjes R, Mahgoub AE, Aro AR. Staff views about the quality of the communicable diseases surveillance system in Khartoum state, Sudan, 2005-2007: A qualitative study. East Mediterr Heal J. 2011;17(7):565-9.

26. Kazerooni PA, Nejat M, Akbarpoor M, Sedaghat Z, Fararouei M. Underascertainment, underreporting, representativeness and timeliness of the Iranian communicable disease surveillance system for tuberculosis. Public Health [Internet]. 2019 Jun 1 [cited 2020 Dec 4];171:50-6. Available from: https://pubmed.ncbi.nlm.nih.gov/31100694/

27. Kazerooni PA, Fararouei M, Nejat M, Akbarpoor M, Sedaghat Z. Under-ascertainment, under-reporting and timeliness of Iranian communicable disease surveillance system for zoonotic diseases. Public Health. 2018 Jan 1;154:130-5.

28. Jajosky RA, Groseclose SL. Evaluation of reporting timeliness of public health surveillance systems for infectious diseases. Vol. 4, BMC Public Health. BioMed Central Ltd.; 2004. p. 1-9.

29. Moradi G, Asadi H, Gouya MM, Nabavi M, Norouzinejad A, Karimi M, et al. The communicable diseases surveillance system in iran: Challenges and opportunities. Arch Iran Med. 2019;22(7):361-8.

30. Ismail SA, Abbara A, Collin SM, Orcutt M, Coutts AP, Maziak W, et al. Communicable disease surveillance and control in the context of conflict and mass displacement in Syria. Int J Infect Dis. 2016 Jun 1;47:1522.

31. Abdulrahim N, Alasasfeh I, Khader YS, Iblan I. Knowledge, Awareness, and Compliance of Disease Surveillance and Notification Among Jordanian Physicians in Residency Programs. Inq (United States) [Internet]. 2019 Jun 1 [cited 2020 Dec 20];56:004695801985650. Available from: http://journals.sagepub.com/doi/10.1177/0046958019856508

\section{Tables}


Table 1: Participants' characteristics

\begin{tabular}{|c|c|}
\hline Characteristics & Participants/ total14 \\
\hline \multicolumn{2}{|l|}{ Sex } \\
\hline Male & 7 \\
\hline Female & 7 \\
\hline \multicolumn{2}{|l|}{ District representing } \\
\hline Erbil & 2 \\
\hline Sulaimani & 9 \\
\hline Duhok & 1 \\
\hline Halabja & 2 \\
\hline \multicolumn{2}{|l|}{ Key Informants (KI) } \\
\hline District Surveillance director & 3 \\
\hline District surveillance director & 3 \\
\hline Health centre director & 1 \\
\hline Surveillance executive staff & 7 \\
\hline \multicolumn{2}{|l|}{ Workplace } \\
\hline District CDC & 6 \\
\hline Health centre & 6 \\
\hline Hospital & 2 \\
\hline
\end{tabular}

Table 2: Codes related to staff's perspectives 
Staff perspective about the system

Flexibility of the system The system is unacceptable

The system exists

System has deficiencies

COVID-19

integration into the CDSS
Why Covid-19 didn't integrate to the surveillance system

No integration
"The system is flexible and working, but not acceptable, not acceptable at all, the people do not use it..."

"there is a surveillance system but with some deficiencies"
"Aram: at the beginning the disease became a political issue, and the things went in that directions"

"I think we did something differ and specific regarding data recording and data publishing"

$\begin{array}{ll}\text { Opportunities } & \begin{array}{l}\text { The system } \\ \text { infrastructure }\end{array} \\ \text { Directorial support }\end{array}$

"The existence of the system itself is good"

"Another strength point was the total support of our manager by all available means, by preparing of transporting and administrative facilitating" "the thing that made the surveillance system work smoothly and easily was the presence of the staff who pledge themselves to work voluntarily in surveillance

Dedicated staff

Barriers

Political and
economic interfere

Overload due to high

No. of cases

Timing

Directorial and planning issues

Insufficient understanding of surveillance concept

Lack of doctors' cooperation

Absent of funding and motivation

Deficiency in computer and internet access Staff deficiency

Recommendations "the problem COVID-19 is a health issue but also before that is an economical issue then it is a political issue, now the COVID-19 is run by the politicians"

"Due to the overload of work and inability to keep all those files we chose another mechanism"

"It was hard copy paper work, not software or electronic reporting, it was needing time"

"Everything here is centralized. Authority is not decentralized"

"many did not understand the concept of surveillance"

"In all our meeting we discussed it, it cannot be solved, the doctors are not cooperating"

"No encouragement for the workers in communicable disease surveillance"

"It was expected that all logistics and computers to be sent to us but nothing was received yet"

"absent of necessary staff, absent of required fund, the barriers regarding logistics, transportation and reductions of training and recent economic issues have a great effect that made the system to be weak"

Translate guides into
Kurdish

Hospital health focal unit
"We need a guideline for surveillance to be in Kurdish language not in Arabic or English"

"Opening public health units in all hospitals"

"Meet the needs of the department, provide employees" 
More human and

logistic support

needed

More training

courses

Use of Electronic

program

Good plan
"More training is needed"

"Making the surveillance system Electronic will make it tougher than the existing one"

"specific plan is needed, plan to control, plan to the teams work, plan to what program that to be used as Epi Info"

\section{Table 3: Codes related to core and support functions}




\begin{tabular}{|c|c|c|c|}
\hline Main themes & Codes & Sub-codes & Participant quotes \\
\hline \multirow[t]{10}{*}{$\begin{array}{l}\text { Core } \\
\text { activities }\end{array}$} & $\begin{array}{l}\text { Case } \\
\text { detection }\end{array}$ & $\begin{array}{l}\text { Case } \\
\text { definition } \\
\text { exist }\end{array}$ & $\begin{array}{l}\text { "the case definition that we have is that the ministry of health of Baghdad has sent to } \\
\text { us. it is the same that WHO has approved" }\end{array}$ \\
\hline & & $\begin{array}{l}\text { Source of } \\
\text { case- } \\
\text { definition }\end{array}$ & $\begin{array}{l}\text { "As our unit I did not receive anything ... but as the surveillance unit, I didn't get the } \\
\text { case definition" }\end{array}$ \\
\hline & & $\begin{array}{l}\text { lack of case- } \\
\text { definition } \\
\text { guide in- } \\
\text { health } \\
\text { facilities }\end{array}$ & \\
\hline & $\begin{array}{l}\text { Case- } \\
\text { confirmation }\end{array}$ & $\begin{array}{l}\text { Laboratory } \\
\text { case } \\
\text { confirmation }\end{array}$ & $\begin{array}{l}\text { "regarding the laboratory activities we didn't have any problems sampling and } \\
\text { transporting and machines all were good" } \\
\text { "when much more samples were taken (out of the lab) capacities, more than } 2 \text { weeks } \\
\text { were needed to get the results" }\end{array}$ \\
\hline & & lab problems & \\
\hline & Reporting & $\begin{array}{l}\text { Reporting } \\
\text { Mechanism }\end{array}$ & $\begin{array}{l}\text { "the reporting was very clear and obvious indeed } \\
\text { where there is COVID-19 how it refers to where how } \\
\text { tests and who report and to where is clear. In ... the } \\
\text { work is central if it was suspected case, they would } \\
\text { take a sample for testing, then they would document } \\
\text { it, and report it to us" } \\
\text { "it wasn't arriving on time. It was hard copy paper } \\
\text { work, not software or electronic reporting, it was } \\
\text { needing time" }\end{array}$ \\
\hline & Data analysis & $\begin{array}{l}\text { Performing } \\
\text { data } \\
\text { analysis }\end{array}$ & $\begin{array}{l}\text { "the data analysis is just performed in district level" } \\
\text { "we do not have a right to reach the data even to get or analyze our data, under the } \\
\text { name of national security" }\end{array}$ \\
\hline & & $\begin{array}{l}\text { Data analysis } \\
\text { problems }\end{array}$ & \\
\hline & Feedbacks & & $\begin{array}{l}\text { "I can say there was a regular weekly feedback from Baghdad at the end of the week } \\
\text { in Thursday this is nationally but as a local government there is no feedbacks from } \\
\text { ministry of health" }\end{array}$ \\
\hline & $\begin{array}{l}\text { Epidemic- } \\
\text { preparedness }\end{array}$ & & $\begin{array}{l}\text { "Waleed: in CDC in our district there is no prepared plan for communicable disease } \\
\text { emergencies" }\end{array}$ \\
\hline $\begin{array}{l}\text { Support } \\
\text { activities }\end{array}$ & $\begin{array}{l}\text { Staff- } \\
\text { involvement } \\
\text { Supervision }\end{array}$ & & $\begin{array}{l}\text { "I love my job surveillance is important needs more support by the authorities" } \\
\text { "From Baghdad there is regular visits ... But during this pandemic due to the busyness } \\
\text { of the unit we were unable to visit all places regularly. } \\
\text { "all swap-taking staff were trained before start their work...The training was done by } \\
\text { expert doctor" }\end{array}$ \\
\hline
\end{tabular}

\section{Supplementary Files}

This is a list of supplementary files associated with this preprint. Click to download. 
- Appendix.docx

Page 16/16 